\title{
Tackling Unwanted Proteolysis in Plant Production Hosts Used for Molecular Farming
}

\author{
Manoj K. Mandal, Houtan Ahvari, Stefan Schillberg and Andreas Schiermeyer* \\ Department of Plant Biotechnology, Fraunhofer Institute for Molecular Biology and Applied Ecology, Aachen, Germany
}

Although the field of molecular farming has significantly matured over the last years, some obstacles still need to be resolved. A major limiting factor for a broader application of plant hosts for the production of valuable recombinant proteins is the low yield of intact recombinant proteins. These low yields are at least in part due to the action of endogenous plant proteases on the foreign recombinant proteins. This mini review will present the current knowledge of the proteolytic enzymes involved in the degradation of different target proteins and strategies that are applied to suppress undesirable proteolytic activities in order to safeguard recombinant proteins during the production

OPEN ACCESS

Edited by:

Eugenio Benvenuto,

Italian National Agency for New Technologies, Energy and Sustainable

Economic Development, Italy

Reviewed by:

Frank Sainsbury,

The University of Queensland,

Australia

Philippe V. Jutras,

Laval University, Canada

Mathew Paul,

St George's University of London, UK

*Correspondence:

Andreas Schiermeyer

andreas.schiermeyer@ime.fraunhofer.de

Specialty section:

This article was submitted to

Plant Biotechnology,

a section of the journal

Frontiers in Plant Science

Received: 14 December 2015

Accepted: 19 February 2016

Published: 08 March 2016

Citation:

Mandal MK, Ahvari H, Schillberg S and Schiermeyer A (2016) Tackling Unwanted Proteolysis in Plant

Production Hosts Used for Molecular

Farming. Front. Plant Sci. 7:267. doi: 10.3389/fpls.2016.00267 process.

Keywords: antibodies, biopharmaceuticals, degradation, protease inhibitors, proteases, recombinant proteins, tobacco

\section{INTRODUCTION}

As the field of plant molecular farming has evolved over the last two decades, many obstacles have been overcome, leading to the first approval of a biopharmaceutical protein for human therapy in 2012 and additional candidates being evaluated in clinical trials (Paul and Ma, 2011). Although plant cells have been successfully engineered to humanize the N-glycan modification of recombinant proteins (Castilho and Steinkellner, 2012) and different protocols have been developed for cGMP compliant production (Fischer et al., 2012), an important issue limiting the broader adoption of plant molecular farming remains: the relatively low yield of recombinant proteins. Plant cells, especially the lytic vacuole and the apoplast, are rich in proteolytic enzymes of diverse classes (Goulet et al., 2012). Interestingly, the first approved biopharmaceutical protein made from plant cells is a lysosomal acidic beta-glucocerebrosidase, taliglucerase alfa, a human enzyme that is used in enzyme replacement therapy for Gaucher patients (Shaaltiel et al., 2007) and has evolved to withstand the harsh hydrolytic environment of the lysosome. Other target molecules like full-size IgG antibodies have frequently been reported to suffer from proteolytic degradation (Donini et al., 2015) irrespective of the plant system that has been used for production. In addition to reduced yields of the target protein, proteolytic processing might also lead to the formation of degradation products that have very similar physico-chemical properties as the intact target protein and are therefore difficult to remove during downstream processing. Several strategies are currently evaluated to safeguard the target protein against degradation that should ultimately lead to the development of improved plant host systems.

Abbreviations: ACT, antichymotrypsin; CDI, cathepsin D inhibitor; DFP, diisopropylfluorophosphate; DSPA, Desmodus rotundus plasminogen activator; ERT, enzyme replacement therapy; Fab, fragment antigen-binding; Fc, fragment crystallizable; GM-CSF, granulocyte-macrophage colony-stimulating factor; HC, heavy chain; Ig, immunoglobuline; IL-10, interleukin-10; mAb, monoclonal antibody; PLCP, papain-like cysteine protease; PMSF, phenylmethanesulfonyl fluoride; PVP, polyvinylpyrrolidone. 


\section{PROTEOLYTIC DEGRADATION OF RECOMBINANT PROTEINS}

Many candidate biopharmaceutical proteins such as plasminogen activators (Schiermeyer et al., 2005), cytokines (Sirko et al., 2011), human serum albumin (Sun et al., 2011), and monoclonal antibodies (Stevens et al., 2000; Sharp and Doran, 2001; Muynck et al., 2009) have been shown to undergo proteolytic processing to different degrees when they are produced in plant cells. The following section presents examples of the proteolytic degradation of recombinant proteins produced in plant cells and the proteolytic enzymes involved.

Monoclonal antibodies currently represent the largest class of biopharmaceuticals and thus also represent attractive target molecules for plant production platforms. However, plantproduced full-length antibodies often show degradation of their heavy chains, whereas the light chains usually remain intact. It has been known for a long time that plant cysteine proteases of the papain family are able to cleave immunoglobulins within the hinge region of their heavy chains to yield Fab and Fc fragments (Porter, 1959). Other proteases cleave immunoglobulins in the same region but at slightly different sites (Gorevic et al., 1985), which indicates that the cleavage depends not only on specific sequence recognition sites but also on the open and accessible conformation of the hinge region and, in some cases, other solvent-exposed loops. It is therefore not surprising that several research groups reported the processing of plant-produced recombinant IgG antibodies into $\mathrm{Fc}, \mathrm{Fab}, \mathrm{F}\left(\mathrm{ab}^{\prime}\right)_{2}$ and other cleavage products (Hehle et al., 2014). Approximately 90\% of the heavy chain of the human H10 IgG1 $\lambda$ monoclonal antibody was cleaved inside the cells of tobacco plants (Villani et al., 2009). The murine IgG1 monoclonal antibody MGR48 was cleaved in the hinge region under acidic conditions when it was spiked into crude leaf extracts from Nicotiana tabacum (Stevens et al., 2000). The authors of that study also noted that the proteolytic activity was higher in older leaves than in younger leaves. A systematic analysis of the murine antibody (IgG1) Guy's 13 produced in the tobacco production systems hairy roots, shooty teratoma, and suspension cells indicated that similar degradation products could be identified in all systems (Sharp and Doran, 2001). That study also established that the proteolytic processing occurs along the secretory pathway of the cell and in the apoplast. Similarly, degradation products of the

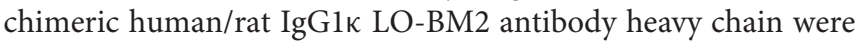
identified in the intercellular wash fluid of transgenic N. tabacum plants and the spent cell culture medium of transgenic tobacco BY-2 suspension cells (Muynck et al., 2009). Most reports on the production of immunoglobulins in plants have been focused on the IgG1 isotype. However, for certain applications, other isotypes might also be of interest (Salfeld, 2007). A recent publication therefore compared the stability of human IgG1, IgG2, and IgG4 monoclonal antibodies in the spent culture medium of tobacco BY-2 suspension cells (Magy et al., 2014). This analysis revealed a significantly higher accumulation of the IgG1 isotype in the culture medium $(10 \mathrm{mg} / \mathrm{L})$ compared with the IgG2 $(5.4 \mathrm{mg} / \mathrm{L})$ and $\mathrm{IgG} 4(0.9 \mathrm{mg} / \mathrm{L})$ isotypes. However, when the same set of antibodies was expressed in Arabidopsis thaliana suspension cells, no significant differences in accumulation were recognized. The accumulation of all isotypes was approximately $3 \mathrm{mg} / \mathrm{L}$ in the culture medium.

Because plant genomes encode several hundred proteolytic enzymes (van der Hoorn, 2008), it is challenging to identify the protease(s) that are responsible for the degradation of a given recombinant protein. It has been demonstrated that the proteolytic processing of the heavy chain of the

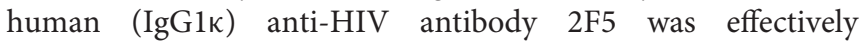
inhibited by phenylmethanesulfonyl fluoride (PMSF) or diisopropylfluorophosphate (DFP), two irreversible inhibitors of serine proteases (Mandal et al., 2014; Niemer et al., 2014). Similarly, it has been shown that the degradation of human IgG3 antibodies spiked into spent culture medium from tobacco BY-2 cells and other recombinant proteins, such as human $\alpha_{1}$-antitrypsin or BSA, spiked into the intercellular washing fluid of tobacco plants was partially inhibited by the addition of PMSF (Delannoy et al., 2008; Navarre et al., 2012; Castilho et al., 2014).

Because most pharmaceutical proteins are glycoproteins, their recombinant counterparts are targeted to the secretory route to obtain the desired glycan modification in the ER, Golgi apparatus and downstream compartments. Therefore, knowledge of secreted proteases and those residing in cell compartments along the secretory pathway is of critical importance to develop suitable strategies for the stabilization of recombinant proteins. Mass spectrometry based secretome analysis of tobacco BY-2 spent culture medium (Navarre et al., 2012), hydroponic culture medium of tobacco plants (Madeira et al., 2016; Wendlandt et al., 2016) and intercellular washing fluid of $N$. benthamiana leaves (Goulet et al., 2010a) revealed the presence of subtilisinlike proteases, serine carboxypeptidases, papain-like cysteine proteases (PLCP) and homologs of the CND41 aspartic protease belonging to the S8, S10, C1 and the A1 family of proteases according to the MEROPS classification (Rawlings et al., 2012). A proteomic survey of the spent culture medium from rice cells revealed the secretion of PLCPs, EP3A, and Rep-1 into the culture medium (Kim et al., 2008a). A specific member of the PLCP family, CysP6 from N. tabacum, has been implicated in the degradation of recombinant human interleukin-10 (IL10) within the endoplasmic reticulum of the cell (Duwadi et al., 2015). A legumain-like cysteine protease belonging to the C13 family according to the MEROPS classification was most likely responsible for the degradation of recombinant equistatin produced in the leaf tissue of Solanum tuberosum (Outchkourov et al., 2003). The degradation of a recombinant plasminogen activator (DSPA $\alpha 1)$ produced in tobacco cells has been shown to be reduced in the presence of EDTA, indicating the involvement of a matrix-metalloprotease in the degradation of DSPA $\alpha 1$ (Schiermeyer et al., 2005; Mandal et al., 2010). In vitro studies using recombinant proteolytic enzymes confirmed that two serine proteases, subtilisin (S8 family) and chymotrypsin (S1 family), and two PLCPs (C1 family), cathepsin B and cathepsin L, were able to cleave the 2F5 antibody HC within its CDR-H3 domain (Niemer et al., 2014). 


\section{STRATEGIES TO COMBAT PROTEOLYSIS}

During the past two decades various strategies have been developed and tested to reduce the proteolytic activity in a variety of plant expression systems to increase accumulation levels of recombinant biopharmaceuticals. The following sections describe these efforts in more detail and an overview of the different approaches to reduce the proteolytic activity in plant tissue and cell cultures is provided in Table $\mathbf{1}$.

\section{SUPPLEMENTATION OF STABILIZING AGENTS}

The use of suspension cultures for plant cells and organs to produce recombinant proteins enables the addition of protein-stabilizing agents to the culture medium. It has been demonstrated that the heavy chain of a murine IgG1 antibody could be stabilized in the spent culture medium of tobacco hairy roots by the addition of gelatin or polyvinylpyrrolidone (PVP), thereby increasing the production level up to nine-fold (Wongsamuth and Doran, 1997). Similarly the accumulation level of the anti-vitronectin human IgG1 $\mathrm{mAb}$ M12 in the culture medium of hairy roots increased twofold when PVP was added to the culture medium (Häkkinen et al., 2014). The addition of PVP to the culture medium of transgenic tobacco NT-1 cells expressing a murine IgG1 antibody led even to a 35 -fold increase in antibody heavy chain accumulation in the culture medium (LaCount et al., 1997). By supplementing the culture medium of transgenic tobacco NT-1 cells with bovine serum albumin, a two-fold increase in the accumulation of extracellular human GM-CSF was achieved (James et al., 2000). Likewise, the addition of human serum albumin to the culture medium of transgenic moss (Physcomitrella patens) cells expressing the human vascular endothelial growth factor enhanced its production levels three-fold (Baur et al., 2005). Whether the above-mentioned substances exert an inhibitory effect on proteolytic enzymes has not yet been analyzed, but the proteinaceous substances might act as an alternative substrate for extracellular proteases, thereby stabilizing the protein of interest.

\section{CO-EXPRESSION OF PROTEASE INHIBITORS}

Different strategies have been tested to reduce the unwanted proteolysis of recombinant proteins in plant cells, such as the co-expression of protease inhibitors together with the protein of interest. In particular, protease inhibitors with specificity for cysteine, serine or aspartic proteases have been deployed for this purpose. It has been reported that co-expression of the Kunitz-type (I3 family according to the MEROPS classification) cathepsin D inhibitor (SlCDI) from tomatoes with human $\alpha_{1}$ antichymotrypsin $(\alpha 1-\mathrm{ACT})$ stabilizes the latter and leads to a 2.5 -fold increase in its accumulation in potato leaves (Goulet et al., 2010b). In a follow-up study, the transient expression of SlCDI or tomato cystatin SlCYS9 (I25 family) was investigated for the potential to stabilize the murine C5-1 IgG monoclonal antibody in N. benthamiana. Whereas the expression of both inhibitors led to increased accumulation of the antibody light chain, higher production of the heavy chain could only be documented by the co-expression of SlCDI (Goulet et al., 2012). In a recent report, another member of the tomato cystatin family, SlCYS8, was used for transient co-expression with the C5-1 antibody in N. benthamiana. The accumulation of the C51 antibody increased approximately $40 \%$ on the whole plant scale. However, it has been recognized that the stabilizing effect of this cystatin is confined to the younger leaves of the plant. In older leaves, the SlCYS8 levels were considerably lower and increased PLCPs activity has been documented in these leaves (Robert et al., 2013). Constitutive expression of the rice cysteine protease inhibitor oryzacystatin-I resulted in an increased accumulation and higher activity of the model protein glutathione reductase in tobacco plants compared with non-transgenic controls (Pillay et al., 2012). The co-expression of a synthetic construct containing trypsin and chymotrypsin inhibitor domains from the proteinase inhibitor II (I20 family) gene from $N$. alata with recombinant human granulocytemacrophage colony-stimulating factor (hGM-CSF) led to a twofold increase in the accumulation of secreted hGM-CSF in rice suspension cultures (Kim et al., 2008b). Co-secretion of the soybean Bowman-Birk serine protease inhibitor (I12 family) together with recombinant human single-chain IgG1 or fullsize IgG4 antibodies from the roots of transgenic tobacco plants increased the accumulation of the antibodies 2- to 2.5-fold (Komarnytsky et al., 2006).

\section{GENE KNOCKDOWN}

Another promising strategy to reduce the proteolytic degradation of recombinant proteins is to knockdown the expression of protease-encoding genes. This strategy was introduced by Kim et al. (2008a) to suppress the expression of the cysteine protease gene Rep-1 by RNAi in rice suspension cells to improve the production of hGM-CSF. In that report, the authors used the rice amylase 3D promoter to drive the expression of hGM-CSF upon induction by sugar starvation. However, sugar starvation resulted in an accumulation of a cysteine protease from the C1A family encoded by the Rep-1 gene. The expression of Rep-1 was suppressed by post-transcriptional gene silencing using an intron-containing self-complementary hairpin RNA (ihpRNA) construct specific for Rep-1. This strategy resulted in a twofold higher accumulation of hGM-CSF in the rice cell culture medium compared with its expression in a non-silenced cell line. A similar approach has been used for intact plants, where the RNAi-mediated silencing of another cysteine protease-encoding gene, CysP6, improved the accumulation of recombinant human IL-10 in tobacco leaves by approximately 1.6-fold (Duwadi et al., 2015). A somewhat broader protease silencing approach was followed by simultaneous silencing of four protease genes (NtAP, $\mathrm{NtCP}, \mathrm{NtMMP}$, and NtSP) coding for proteases from four catalytic classes (aspartic, cysteine, metallo- and serine proteases) through the expression of the corresponding antisense sequences in tobacco BY-2 cells (Mandal et al., 2014). The study showed 
TABLE 1 | Strategies to reduce proteolysis in plant tissues and cell cultures.

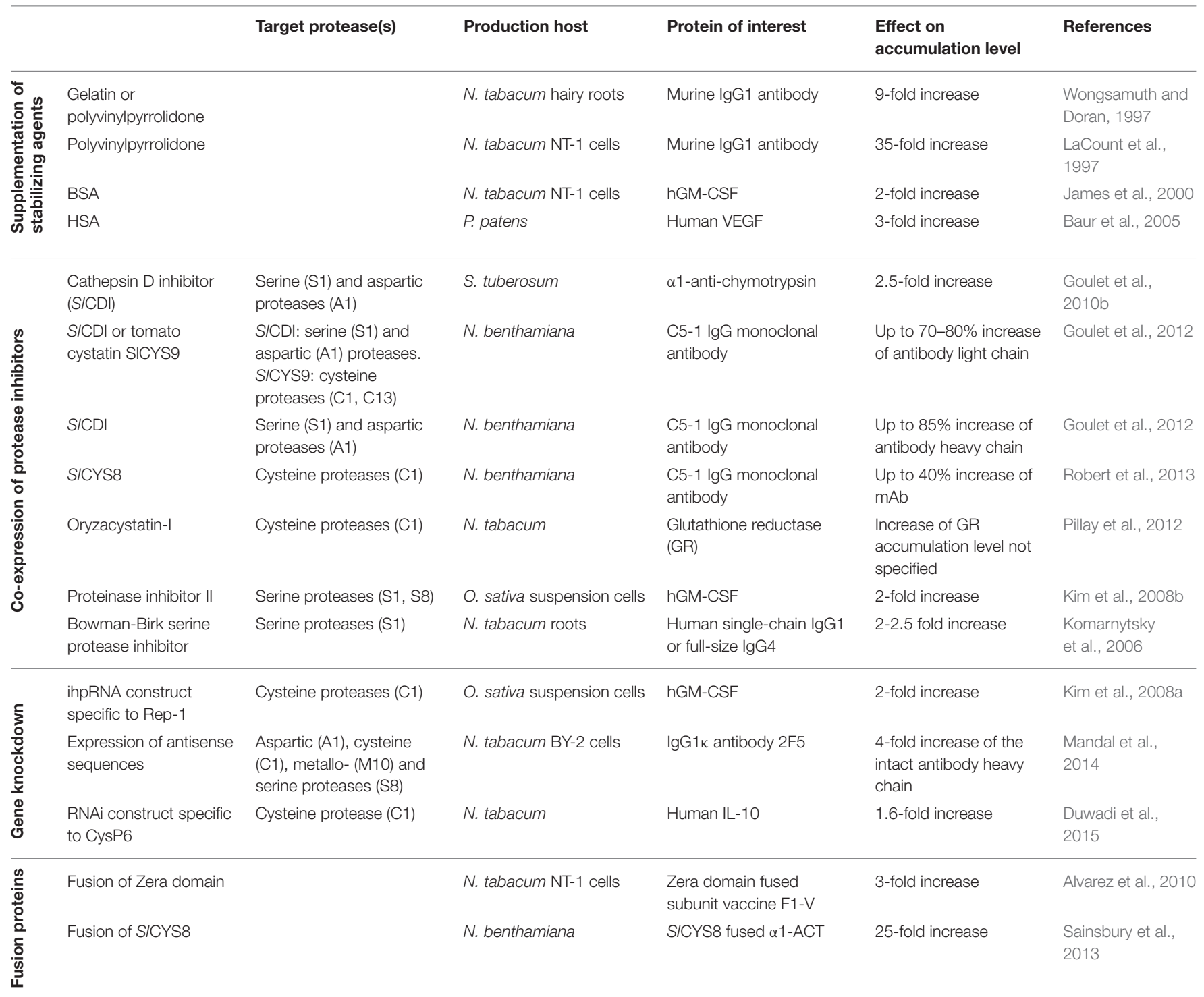

that the culture medium of the antisense RNA-expressing BY-2 cells had a lower level of total proteolytic activity than did wildtype BY-2 cells. When this transgenic BY-2 cell line was used

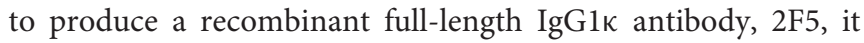
resulted in a four-fold higher accumulation of the intact antibody heavy chain compared with wild type cells expressing the same antibody.

With the introduction of different gene targeting strategies based on sequence-specific nucleases, it is now possible to disrupt any protease gene to completely knockout its activity (Fichtner et al., 2014). Although this technology has not yet been applied to protease genes, targeting has been used to knockout two $\alpha(1,3)$-fucosyltransferases and two $\beta(1,2)$-xylosyltransferases in $N$. benthamiana to engineer plants that are devoid of plantspecific N-glycosylation patterns (Li et al., 2016). It is therefore only a matter of time before this technology will be applied to generate plants in which specific protease genes will be disrupted.

\section{SUBCELLULAR TARGETING AND FUSION PROTEINS}

To protect recombinant proteins from degradation in the apoplast or vacuole, targeting strategies have been developed to sequester the target protein from these hydrolytic cellular compartments. The retention of recombinant proteins in the ER or ER-derived structures has been proven to be particularly beneficial (Conrad and Fiedler, 1998). As plant seeds have evolved to store proteins in large quantities, a fusion strategy using the maize seed storage protein, $\gamma$-zein, has been developed. When the N-terminal Zera ( $\gamma$-zein ER-accumulating) domain was fused to target proteins, the proteins accumulated in ERderived protein bodies. The fusion of the Zera domain with the subunit vaccine F1-V from Yersinia pestis led to the formation of protein bodies and a three-fold higher accumulation of the fusion protein in tobacco NT-1 suspension cells compared to F1-V alone 
(Alvarez et al., 2010). Similar results were obtained in transiently transformed $N$. benthamiana and stably transformed alfalfa (Medicago sativa) plants. Likewise, the fusion of target proteins with hydrophobin I from Trichoderma reesei facilitated the formation of protein bodies in N. tabacum and N. benthamiana and increased the product yields (Joensuu et al., 2010; Gutiérrez et al., 2013).

In addition to the co-expression strategy with protease inhibitors described above, the tomato cystatin SlCYS8 has been used to produce a fusion protein with human $\alpha 1-\mathrm{ACT}$. This fusion protein accumulated at up to 25-fold higher levels compared with free $\alpha 1$-ACT (Sainsbury et al., 2013). However, in this case, the stabilizing effect was shown to be independent of the inhibition of cysteine proteases, as a fusion with a mutant, inactive, SlCYS8 protein also displayed a similar stabilizing activity. The authors therefore speculated that the fusion with SlCYS8 stabilizes the tertiary structure of $\alpha 1$-ACT and thereby prevents its attack by hydrolytic enzymes.

\section{REFERENCES}

Alvarez, M. L., Topal, E., Martin, F., and Cardineau, G. A. (2010). Higher accumulation of $\mathrm{F} 1-\mathrm{V}$ fusion recombinant protein in plants after induction of protein body formation. Plant Mol. Biol. 72, 75-89. doi: 10.1007/s11103-0099552-4

Baur, A., Reski, R., and Gorr, G. (2005). Enhanced recovery of a secreted recombinant human growth factor using stabilizing additives and by coexpression of human serum albumin in the moss Physcomitrella patens. Plant Biotechnol. J. 3, 331-340. doi: 10.1111/j.1467-7652.2005.00127.x

Castilho, A., and Steinkellner, H. (2012). Glyco-engineering in plants to produce human-like N-glycan structures. Biotechnol. J. 7, 1088-1098. doi: 10.1002/biot.201200032

Castilho, A., Windwarder, M., Gattinger, P., Mach, L., Strasser, R., Altmann, F., et al. (2014). Proteolytic and N-Glycan processing of human $\alpha 1$-antitrypsin expressed in nicotiana benthamiana. Plant Physiol. 166, 1839-1851. doi: 10.1104/pp.114.250720

Conrad, U., and Fiedler, U. (1998). Compartment-specific accumulation of recombinant immunoglobulins in plant cells: an essential tool for antibody production and immunomodulation of physiological functions and pathogen activity. Plant Mol. Biol. 38, 101-109. doi: 10.1023/A:1006029617949

Delannoy, M., Alves, G., Vertommen, D., Ma, J., Boutry, M., and Navarre, C. (2008). Identification of peptidases in Nicotiana tabacum leaf intercellular fluid. Proteomics 8, 2285-2298. doi: 10.1002/pmic.200700507

Donini, M., Lombardi, R., Lonoce, C., Di Carli, M., Marusic, C., Morea, V., et al. (2015). Antibody proteolysis: a common picture emerging from plants. Bioengineered 6, 299-302. doi: 10.1080/21655979.2015.1067740

Duwadi, K., Chen, L., Menassa, R., and Dhaubhadel, S. (2015). Identification, characterization and down-regulation of cysteine protease genes in tobacco for use in recombinant protein production. PLOS ONE 10:e0130556. doi: 10.1371/journal.pone.0130556

Fichtner, F., Urrea Castellanos, R., and Ülker, B. (2014). Precision genetic modifications: a new era in molecular biology and crop improvement. Planta 239, 921-939. doi: 10.1007/s00425-014-2029-y

Fischer, R., Schillberg, S., Hellwig, S., Twyman, R. M., and Drossard, J. (2012). GMP issues for recombinant plant-derived pharmaceutical proteins. Biotechnol. Adv. 30, 434-439. doi: 10.1016/j.biotechadv.2011.08.007

Gorevic, P. D., Prelli, F. C., and Frangione, B. (1985). Immunoglobulin G (IgG). Meth. Enzymol. 116, 3-25. doi: 10.1016/S0076-6879(85)16003-9

Goulet, C., Benchabane, M., Anguenot, R., Brunelle, F., Khalf, M., and Michaud, D. (2010b). A companion protease inhibitor for the protection of cytosoltargeted recombinant proteins in plants. Plant Biotechnol. J. 8, 142-154. doi: 10.1111/j.1467-7652.2009.00470.x
Based on the above-discussed strategies that can be used to prevent the proteolytic degradation of recombinant proteins, it is clear that there is no "magic bullet" that can stabilize all target proteins. Instead, an individual strategy has to be devised for each recombinant protein of interest. However, the tools described above should provide a suitable selection of procedures to tackle this important issue.

\section{AUTHOR CONTRIBUTIONS}

All authors listed, have made substantial, direct and intellectual contribution to the work, and approved it for publication.

\section{ACKNOWLEDGMENTS}

We gratefully acknowledge the financial support provided by the Federal Ministry of Education and Research (BMBF) within the ERA-IB 3 program (PRODuCE project, 031A219A).

Goulet, C., Goulet, C., Goulet, M.-C., and Michaud, D. (2010a). 2-DE proteome maps for the leaf apoplast of Nicotiana benthamiana. Proteomics 10, 2536-2544. doi: 10.1002/pmic.200900382

Goulet, C., Khalf, M., Sainsbury, F., D’Aoust, M.-A., and Michaud, D. (2012). A protease activity-depleted environment for heterologous proteins migrating towards the leaf cell apoplast. Plant Biotechnol. J. 10, 83-94. doi: 10.1111/j.14677652.2011.00643.x

Gutiérrez, S. P., Saberianfar, R., Kohalmi, S. E., and Menassa, R. (2013). Protein body formation in stable transgenic tobacco expressing elastin-like polypeptide and hydrophobin fusion proteins. BMC Biotechnol. 13:40. doi: 10.1186/14726750-13-40

Häkkinen, S. T., Raven, N., Henquet, M., Laukkanen, M.-L., Anderlei, T., Pitkänen, J.-P., et al. (2014). Molecular farming in tobacco hairy roots by triggering the secretion of a pharmaceutical antibody. Biotechnol. Bioeng. 111, 336-346. doi: 10.1002/bit.25113

Hehle, V. K., Lombardi, R., van Dolleweerd, C. J., Paul, M. J., Di Micco, P., Morea, V., et al. (2014). Site-specific proteolytic degradation of IgG monoclonal antibodies expressed in tobacco plants. Plant Biotechnol. J. 13, 235-245. doi: 10.1111/pbi.12266

James, E. A., Wang, C., Wang, Z., Reeves, R., Shin, J. H., Magnuson, N. S., et al. (2000). Production and characterization of biologically active human GM-CSF secreted by genetically modified plant cells. Protein Expr. Purif. 19, 131-138. doi: $10.1006 /$ prep.2000.1232

Joensuu, J. J., Conley, A. J., Lienemann, M., Brandle, J. E., Linder, M. B., and Menassa, R. (2010). Hydrophobin fusions for high-level transient protein expression and purification in Nicotiana benthamiana. Plant Physiol. 152, 622-633. doi: 10.1104/pp.109.149021

Kim, N. S., Kim, T. G., Kim, O. H., Ko, E. M., Jang, Y. S., Jung, E. S., et al. (2008a). Improvement of recombinant hGM-CSF production by suppression of cysteine proteinase gene expression using RNA interference in a transgenic rice culture. Plant Mol. Biol. 68, 263-275. doi: 10.1007/s11103-008-9367-8

Kim, T. G., Lee, H. J., Jang, Y. S., Shin, Y. J., Kwon, T. H., and Yang, M. S. (2008b). Co-expression of proteinase inhibitor enhances recombinant human granulocyte-macrophage colony stimulating factor production in transgenic rice cell suspension culture. Protein Expr. Purif. 61, 117-121. doi: 10.1016/j.pep.2008.06.005

Komarnytsky, S., Borisjuk, N., Yakoby, N., Garvey, A., and Raskin, I. (2006). Cosecretion of protease inhibitor stabilizes antibodies produced by plant roots. Plant Physiol. 141, 1185-1193. doi: 10.1104/pp.105.074419

LaCount, W., An, G. H., and Lee, J. M. (1997). The effect of polyvinylpyrrolidone (PVP) on the heavy chain monoclonal antibody production from plant suspension cultures. Biotechnol. Lett. 19, 93-96. doi: 10.1023/A:1018383 524389 
Li, J., Stoddard, T. J., Demorest, Z. L., Lavoie, P.-O., Luo, S., Clasen, B. M., et al. (2016). Multiplexed, targeted gene editing in Nicotiana benthamiana for glyco-engineering and monoclonal antibody production. Plant Biotechnol. J. 14, 533-542. doi: 10.1111/pbi.12403

Madeira, L. M., Szeto, T. H., Henquet, M., Raven, N., Runions, J., Huddleston, J., et al., (2016). High-yield production of a human monoclonal IgG by rhizosecretion in hydroponic tobacco cultures. Plant Biotechnol. J. 14, 615-624. doi: $10.1111 /$ pbi.12407

Magy, B., Tollet, J., Laterre, R., Boutry, M., and Navarre, C. (2014). Accumulation of secreted antibodies in plant cell cultures varies according to the isotype, host species and culture conditions. Plant Biotechnol. J. 12, 457-467. doi: 10.1111/pbi.12152

Mandal, M. K., Fischer, R., Schillberg, S., and Schiermeyer, A. (2010). Biochemical properties of the matrix metalloproteinase NtMMP1 from Nicotiana tabacum cv. BY-2 suspension cells. Planta 232, 899-910. doi: 10.1007/s00425-010-1221-y

Mandal, M. K., Fischer, R., Schillberg, S., and Schiermeyer, A. (2014). Inhibition of protease activity by antisense RNA improves recombinant protein production in Nicotiana tabacum cv Bright Yellow 2 (BY-2) suspension cells. Biotechnol. J. 9, 1065-1073. doi: 10.1002/biot.201300424

Muynck, B., de Navarre, C., Nizet, Y., Stadlmann, J., and Boutry, M. (2009). Different subcellular localization and glycosylation for a functional antibody expressed in Nicotiana tabacum plants and suspension cells. Transgenic Res. 18, 467-482. doi: 10.1007/s11248-008-9240-1

Navarre, C., Muynck, B., de Alves, G., Vertommen, D., Magy, B., and Boutry, M. (2012). Identification, gene cloning and expression of serine proteases in the extracellular medium of Nicotiana tabacum cells. Plant Cell Rep. 31, 1959-1968. doi: 10.1007/s00299-012-1308-y

Niemer, M., Mehofer, U., Torres, A., Juan, A., Verdianz, M., Henkel, T., et al. (2014). The human anti-HIV antibodies 2F5, 2G12, and PG9 differ in their susceptibility to proteolytic degradation: down-regulation of endogenous serine and cysteine proteinase activities could improve antibody production in plant-based expression platforms. Biotechnol. J. 9, 493-500. doi: 10.1002/biot.201300207

Outchkourov, N. S., Rogelj, B., Strukelj, B., and Jongsma, M. A. (2003). Expression of sea anemone equistatin in potato. Effects of plant proteases on heterologous protein production. Plant Physiol. 133, 379-390. doi: 10.1104/pp.102. 017293

Paul, M., and Ma, J. K. (2011). Plant-made pharmaceuticals: leading products and production platforms. Biotechnol. Appl. Biochem. 58, 58-67. doi: 10.1002/bab.6

Pillay, P., Kibido, T., Plessis, M., Vyver, C., Beyene, G., Vorster, B. J., et al. (2012). Use of transgenic oryzacystatin-I-expressing plants enhances recombinant protein production. Appl. Biochem. Biotechnol. 168, 1608-1620. doi: 10.1007/s12010-012-9882-6

Porter, R. R. (1959). Hydrolysis of rabbit gamma-globulin and antibodies with crystalline papain. Biochem. J. 73, 119-126. doi: 10.1042/bj0730119

Rawlings, N. D., Barrett, A. J., and Bateman, A. (2012). MEROPS: the database of proteolytic enzymes, their substrates and inhibitors. Nucleic Acids Res. 40, D343-D350. doi: 10.1093/nar/gkr987

Robert, S., Khalf, M., Goulet, M.-C., D’Aoust, M.-A., Sainsbury, F., Michaud, D., et al. (2013). Protection of recombinant mammalian antibodies from development-dependent proteolysis in leaves of Nicotiana benthamiana. PLoS ONE 8:e70203. doi: 10.1371/journal.pone.0070203
Sainsbury, F., Varennes-Jutras, P., Goulet, M.-C., D’Aoust, M.-A., and Michaud, D. (2013). Tomato cystatin SlCYS8 as a stabilizing fusion partner for human serpin expression in plants. Plant Biotechnol. J. 11, 1058-1068. doi: 10.1111/pbi. 12098

Salfeld, J. G. (2007). Isotype selection in antibody engineering. Nat. Biotechnol. 25, 1369-1372. doi: 10.1038/nbt1207-1369

Schiermeyer, A., Schinkel, H., Apel, S., Fischer, R., and Schillberg, S. (2005). Production of Desmodus rotundus salivary plasminogen activator a1 (DSPAa1) in tobacco is hampered by proteolysis. Biotechnol. Bioeng. 89, 848-858. doi: 10.1002/bit.20410

Shaaltiel, Y., Bartfeld, D., Hashmueli, S., Baum, G., Brill-Almon, E., Galili, G., et al. (2007). Production of glucocerebrosidase with terminal mannose glycans for enzyme replacement therapy of Gaucher's disease using a plant cell system. Plant Biotechnol. J. 5, 579-590. doi: 10.1111/j.1467-7652.2007. 00263.x

Sharp, J. M., and Doran, P. M. (2001). Characterization of monoclonal antibody fragments produced by plant cells. Biotechnol. Bioeng. 73, 338-346. doi: 10.1002/bit.1067

Sirko, A., Vanek, T., Gora-Sochacka, A., and Redkiewicz, P. (2011). Recombinant cytokines from plants. Int. J. Mol. Sci. 12, 3536-3552. doi: 10.3390/ijms 12063536

Stevens, L. H., Stoopen, G. M., Elbers, I. J. W., Molthoff, J. W., Bakker, H. A. C. Lommen, A., et al. (2000). Effect of climate conditions and plant developmental stage on the stability of antibodies expressed in transgenic tobacco. Plant Physiol. 124, 173-182. doi: 10.1104/pp.124.1.173

Sun, Q. Y., Ding, L. W., Lomonossoff, G. P., Sun, Y. B., Luo, M., Li, C. Q., et al. (2011). Improved expression and purification of recombinant human serum albumin from transgenic tobacco suspension culture. J. Biotechnol. 155, 164-172. doi: 10.1016/j.jbiotec.2011.06.033

van der Hoorn, R. A. (2008). Plant proteases: from phenotypes to molecular mechanisms. Annu. Rev. Plant Biol. 59, 191-223. doi: 10.1146/annurev.arplant.59.032607.092835

Villani, M. E., Morgun, B., Brunetti, P., Marusic, C., Lombardi, R., Pisoni, I., et al. (2009). Plant pharming of a full-sized, tumour-targeting antibody using different expression strategies. Plant Biotechnol. J. 7, 59-72. doi: 10.1111/j.14677652.2008.00371.x

Wendlandt, T., Moche, M., Becher, D., and Stöhr, C. (2016). A SDD1-like subtilase is exuded by tobacco roots. Funct. Plant Biol. 43, 141-150. doi: 10.1071/fp15211

Wongsamuth, R., and Doran, P. M. (1997). Production of monoclonal antibodies by tobacco hairy roots. Biotechnol. Bioeng. 54, 141-150. 401-415.

Conflict of Interest Statement: The authors declare that the research was conducted in the absence of any commercial or financial relationships that could be construed as a potential conflict of interest.

Copyright (c) 2016 Mandal, Ahvari, Schillberg and Schiermeyer. This is an openaccess article distributed under the terms of the Creative Commons Attribution License (CC BY). The use, distribution or reproduction in other forums is permitted, provided the original author(s) or licensor are credited and that the original publication in this journal is cited, in accordance with accepted academic practice. No use, distribution or reproduction is permitted which does not comply with these terms. 